(3) For example, Creep and Fracture of Metals at High Temperature, section 3 (1959), National Physical Laboratory.

(4) E. L. Robinson: Trans. ASME, Vol. 74 (1952), p. 777 .

(5) J. Miller: $A S T M, S T P$. , No. 165 (1954), p. 40.
(6) F. C. Monkmann and N. J. Grant: Proc. ASTM, Vol. 56 (1956), p. 593

(7) E.S.Maclin: Jour. Metal, Vol.8, No. 2 (1956), p.106.

(8) T. Nishihara, S. Taira, K. Tanaka, and M. Ohnami: Tech. Rep. Engng. Res. Inst., Kyoto Univ., Vo1. 8, No. 2 (1958).

539. $434 / .435: 620.178 .38$

\title{
Dynamic Creep and Fatigue of an 18-8 Mo-Cb Steel at Elevated Temperature*
}

\author{
By Shuji TAIRA** and Ryoichi KoterazawA***
}

\begin{abstract}
Dynamic creep and fatigue tests were carried out with an $18-8 \mathrm{Mo}-\mathrm{Cb}$ steel at a temperature of $650^{\circ} \mathrm{C}$. The results were discussed from the standpoint of the analysis, which had been proposed by the authors previously, concerning the prediction of dynamic creep and fatigue strength from the information on static creep and creep rupture tests together with reversed stress fatigue data. The prediction by the analysis showed a satisfactory agreement with the experimental results as for a practical purpose, although a little discrepancy was observed due to the acceleration of the precipitation hardening by alternating stress.

In order to contribute to clarification of the relation between the precipitation hardening characteristics of the material and its strength characteristics, the electron-microscopic observation of structure, hardness test and creep rupture test after the dynamic creep were carried out. Their results were discussed in connection with the discrepancy between the analysis and experiments.
\end{abstract}

\section{Introduction}

One of the most important problems for the design of elevated temperature devices is the evaluation of strength characteristics of their members under a dynamic load. For this purpose, it is necessary to find the relation between the dynamic and the static strengths of a material, because it offers us the means of prediction of the dynamic strength from the readily available data on static strength. Concerning this problem, the authors have proposed a method of analysis and proved its validity for some materials; low carbon steel, 13 chromium steel and commercially pure titanium ${ }^{(1)-(5)}$. This paper is a continuation of the previous papers and is intended to examine the applicability of the analysis to an austenitic steel, which shows precipitation hardening during the creep process, using an $18-8 \mathrm{Mo}-\mathrm{Cb}$ steel of AISI 318 type.

* Received 30th October, 1960

** Professor, Faculty of Engineering, Kyoto University.

*** Assistant Professor, Faculty of Engineering, Kyoto

University, Sakyo-ku, Kyoto.

\section{Testing apparatus, test material and test specimen}

The testing machine used in this study is the same as the one described in the previous report ${ }^{(2)}$. The test material is an $18-8 \mathrm{Mo}-\mathrm{Cb}$ steel of AISI 318 type and its chemical composition, condition of heat treatment and mechanical properties at room temperature are given in Table 1 . Two different

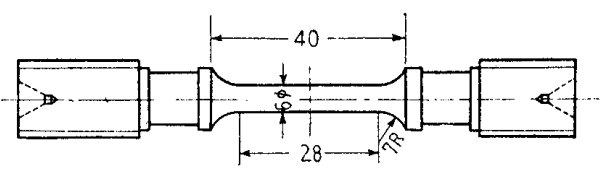

( $A=0,0.22,0.61,0.75$ )

(a) Specimen for creep test

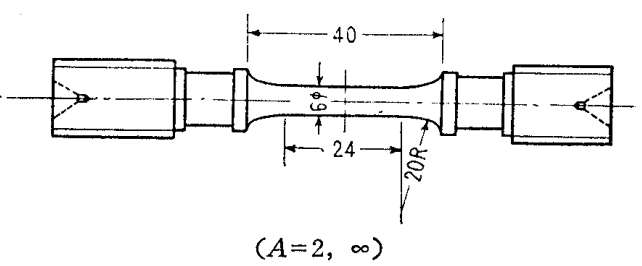

(b) Specimen for fatigue test

Fig. 1 Test specimen 
Table 1 Chemical composition, condition of heat treatment and mechanical properties at room temperature

\begin{tabular}{c|c|c|c|c|c|c|c|c|c|c|c|c|c|c|c|c|c|c|c|c|}
\hline \hline Composition & $\mathrm{C}$ & $\mathrm{Mn}$ & $\mathrm{Si}$ & $\mathrm{P}$ & $\mathrm{S}$ & $\mathrm{Ni}$ & $\mathrm{Cr}$ & $\mathrm{Mo}$ & $\mathrm{Cb}$ & $\mathrm{Cu}$ & $\mathrm{Fe}$ \\
\hline$\%$ & 0.059 & 0.177 & 0.32 & 0.012 & 0.015 & 14.17 & 16.78 & 2.48 & 0.78 & 0.08 & $\mathrm{bal}$ \\
\hline
\end{tabular}

Heat treatment $: 1100^{\circ} \mathrm{C} 2$ hours water quench

\begin{tabular}{c|c}
\hline Tensile strength & $59.0 \mathrm{~kg} / \mathrm{mm}^{2}$ \\
\hline Elongation & $48.0 \%$ \\
\hline Reduction of area & $74.0 \%$ \\
\hline
\end{tabular}

Table 2 Test conditions

Test temperature $: 650^{\circ} \mathrm{C}$, Frequency of alternating stress $: 2000 \mathrm{c} . \mathrm{p} . \mathrm{m}$.

\begin{tabular}{|c|c|c|c|c|c|}
\hline Stress ratio $A$ & $\begin{array}{l}\text { Mean stress } \\
\sigma m \mathrm{~kg} / \mathrm{mm}^{2}\end{array}$ & $\begin{array}{l}\text { Alternating stress } \\
\qquad \sigma a \mathrm{~kg} / \mathrm{mm}^{2}\end{array}$ & $\begin{array}{c}\text { Equivalent static } \\
\text { stress for creep } \\
\sigma e \mathrm{~kg} / \mathrm{mm}^{2}\end{array}$ & $\begin{array}{c}\text { Equivalent static } \\
\text { stress for rupture } \\
\sigma e^{\prime} \mathrm{kg} / \mathrm{mm}^{2}\end{array}$ & $\begin{array}{c}\text { Time to fracture } \\
\text { hr }\end{array}$ \\
\hline $\begin{array}{l}0 \\
0 \\
0 \\
0 \\
0\end{array}$ & $\begin{array}{l}15.0 \\
22.6 \\
22.7 \\
26.7 \\
30.7\end{array}$ & $\begin{array}{l}0 \\
0 \\
0 \\
0 \\
0\end{array}$ & $\begin{array}{l}15.0 \\
22.6 \\
22.7 \\
26.7 \\
30.7\end{array}$ & $\begin{array}{l}22.6 \\
26.7 \\
30.7\end{array}$ & $\begin{array}{r}266 \\
125.5 \\
37.0\end{array}$ \\
\hline $\begin{array}{l}0 \\
0.22 \\
0.22 \\
0.22 \\
0.75\end{array}$ & $\begin{array}{r}33.0 \\
19.0 \\
22.4 \\
25.6 \\
8.8\end{array}$ & $\begin{array}{l}0 \\
4.1 \\
4.9 \\
5.7 \\
6.6\end{array}$ & $\begin{array}{l}33.0 \\
22.7 \\
26.9 \\
30.9 \\
15.0\end{array}$ & $\begin{array}{l}33.0 \\
27.2\end{array}$ & $\begin{array}{l}10.2 \\
130\end{array}$ \\
\hline $\begin{array}{l}0.61 \\
0.61 \\
2.0 \\
2.0 \\
2.0\end{array}$ & $\begin{array}{r}14.4 \\
21.0 \\
7.5 \\
9.0 \\
10.0\end{array}$ & $\begin{array}{r}8.8 \\
12.8 \\
15.0 \\
18.0 \\
20.0\end{array}$ & $\begin{array}{l}22.6 \\
33.0 \\
22.2 \\
26.6 \\
29.6\end{array}$ & $\begin{array}{l}19.0 \\
27.7\end{array}$ & $\begin{array}{l}743 \\
220 \\
\\
19.1 \\
0.12\end{array}$ \\
\hline $\begin{array}{l}\infty \\
\infty \\
\infty \\
\infty\end{array}$ & $\begin{array}{l}0 \\
0 \\
0 \\
0\end{array}$ & $\begin{array}{l}15.0 \\
17.0 \\
18.4 \\
22.4\end{array}$ & & & $\begin{array}{l}12.3 \\
0.016\end{array}$ \\
\hline
\end{tabular}

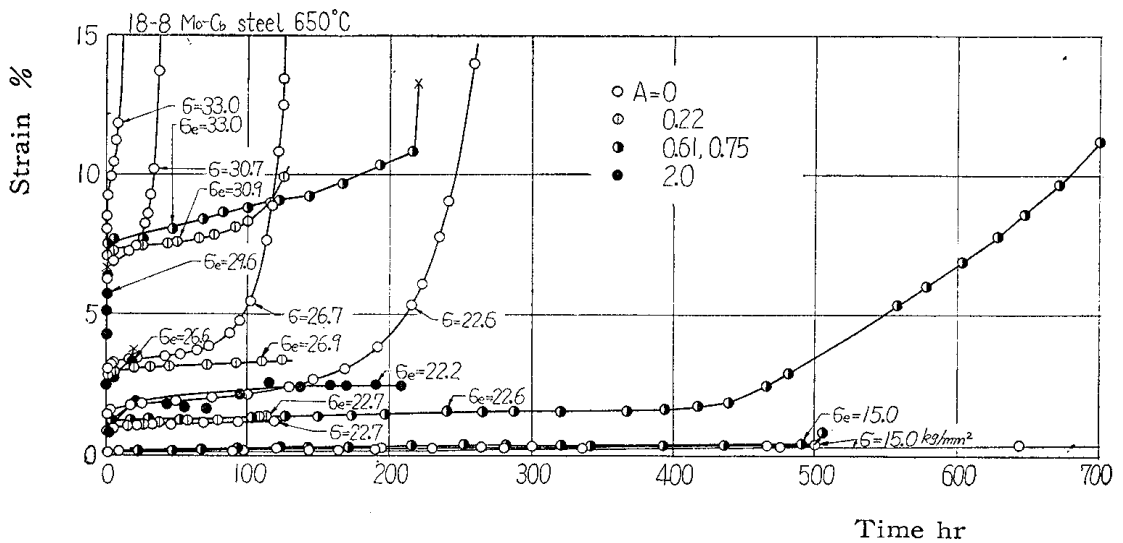

Fig. 2 Creep curves

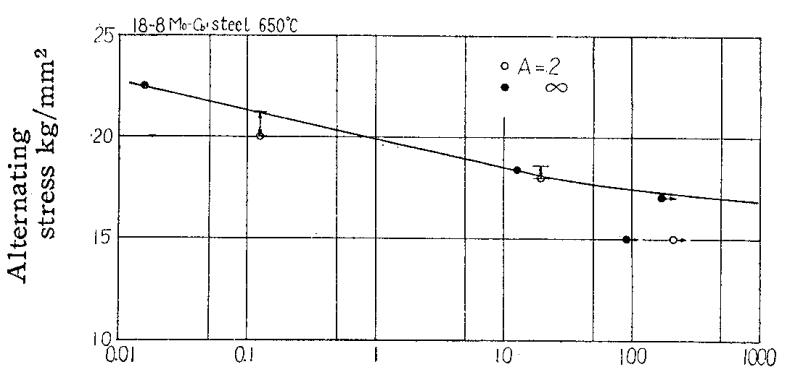

Time to fracture hr

Fig. 3 Alternating stress versus time to fracture diagram for stress ratio $A=2.0$ and $\infty$

shapes of test specimens as shown in Fig. 1, each being $6 \mathrm{~mm}$ in diameter, were used in this study.
The test specimens of the shape (a) were used for tests under stresses with small values of stress ratio $A$ (ratio of alternating stress to mean stress), and those of the shape (b) for large stress ratios as indicated in Fig. 1.

\section{Test results}

The tests were conducted under various conditions of stress ratio $A$, being summarized in Table 2 . The results are illustrated in Figs. 2 and 3. Fig. 2 is the creep curves for dynamic creep of the stress ratio $A$ less than 2.0. Fig. 3 is the diagram showing the relation of alternating stress versus time to fracture, including the test results for the stress ratios of $A=2.0$ and $\infty$. Since the test program of this study had been scheduled on the basis of the equivalent static stress which was defined according to the analysis of dynamic creep proposed by the authors ${ }^{(3)}$, a brief survey will be made of the analysis first.

\subsection{Summary of the analysis on dynamic} creep and dynamic creep rupture

The analysis was divided into two parts, that is, an analysis of dynamic creep and that of dynamic 
creep rupture. The analysis of the dynamic creep was carried out on the basis of the strain hardening theory. In the analysis, the creep strain under a static stress $\sigma$ in the range of transient creep was represented by

$$
\varepsilon=a \sigma^{\alpha} t^{\beta}
$$

where $t$ is time, and $a, \alpha$ and $\beta$ are constants. Then, the creep strain under the dynamic stress with mean stress $\sigma_{m}$ and stress ratio $A$ is of the same magnitude as that of the static creep strain under the stress expressed by the following equation,

$$
\sigma_{e}=\sigma_{m}\left[\frac{1}{2 \pi} \int_{0}^{2 \pi}(1+A \sin \omega t)^{\alpha / \beta} d(\omega t)\right]^{\beta / \alpha}
$$

This stress is called as the equivalent static stress for dynamic creep.

The analysis of dynamic creep rupture was conducted on the basis of the idea of the cumulative creep damage. The rate of increase of the creep damage is expressed by

$$
d \phi_{s} / d t=a_{s}|\sigma|^{\alpha_{s}}
$$

where $a_{s}$ and $\alpha s$ are constants. It is assumed that the fracture will occur when the accumulated creep damage reaches a critical value. In this case, the static stress which will give the same life as in the case of the dynamic stress with mean stress $\sigma_{m}$ and stress ratio $A$, is written as

$$
\sigma_{e}^{\prime}=\sigma_{m}\left[\frac{1}{2 \pi} \int_{0}^{2 \pi}(|1+A \sin \omega t|)^{\alpha_{s}} d(\omega t)\right]^{1 / \alpha_{s}}
$$

This stress is called the equivalent static stress for dynamic creep rupture.

It has been proved by experiments that the equivalent stresses described above can be adopted for the prediction of dynamic creep and life of materials in the case of small stress ratio. The problem of these cases is classified into two categori s, that is, the dynamic creep and the dynamic creep rupture. In the range of large stress ratios, on the other hand, the fatigue damage caused by the alternating component of stress becomes influential to fracture, and the magnitude of alternating stress determines the life, irrespective of the magnitude of mean stress. In this case, the fracture may be called the fatigue fracture.

\subsection{Results and discussion}

The equivalent static stresses for every dynamic stress condition are shown in the 4 th and 5 th columns of Table 2, and are also indicated in Fig. 2. The test conditions have been arranged so as to make it easy to compare the dynamic creep behaviour with the static creep by taking the equivalent stress for dynamic creep same as the stress for static creep.

Looking at Fig. 2, it is found that there is no difference between the dynamic and the static strains before the initiation of the $3 \mathrm{rd}$ stage creep, provided that the equivalent static stress for dynamic condition is the same as the stress for static creep. Moreover, it is seen that the initiation of $3 \mathrm{rd}$ stage seems to be delayed considerably in the dynamic creep as compared with the static case. This delay is remarkable especially in the range of large stress. Consequently, it is understood that the time to fracture is longer in the case of dynamic stress than in the case of static condition.

This is partly due to the fact that the comparison was made on the basis of the equivalent static stress for dynamic creep instead of that for rupture. If the data are replotted on the basis of the equivalent static stress for rupture as Fig. 4, it is evident that the difference between the dynamic and static lives becomes much less than in the case of Fig. 2.

Fig. 3 shows the relation between the stress and the time to fracture in the case of large stress ratios of $A=2.0$ and $\infty$. The stress range indicated by the arrows shows the variation of stress during test caused by the contraction of the cross sectional area of the specimen due to creep deformation. From this figure, it is found that, if the alternating component of stress is chosen as of the same magnitude, specimens fracture at the same time, irrespective of the difference in stress ratio. This complies with the conclusion of the analysis described in the previous section.

\section{Discussion on the influence of precipitation or aging}

As discussed in the preceding section, 18-8 Mo$\mathrm{Cb}$ steel used in this study showed the dynamic creep behaviour which was in good agreement with the results of analysis. However, some discrepancies were observed in the case of fracture under high stress. According to the present information about the characteristics of this type of material ${ }^{(6)}$, it is

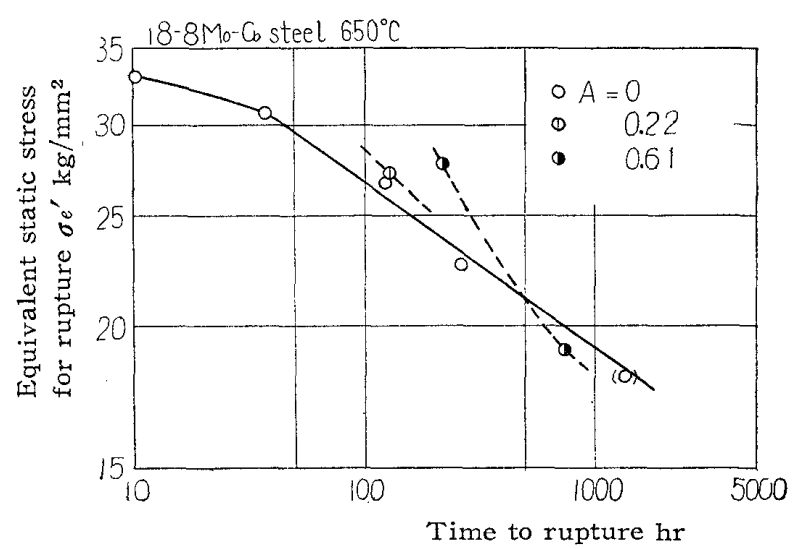

Fig. 4 Equivalent static stress for dynamic creep rupture versus rupture time diagram 
likely that these discrepancies resulted from the precipitation hardening of the material. Therefore, a further discussion will be made to clarify the relation between the precipitation hardening or agehardening of the material and its strength characteristics. For this purpose, the following three sorts of tests were made.

(1) Electron-microscopic examination of structure

(2) Measurement of hardness before and after t'ests

(3) Investigation of static creep behaviour after the dynamic creep test

Discussion will be made on the three items separately.

(1) Electron-microscopic examination of structure

A few examples of electron micrographs are shown in Fig. 6. To make clear the effect of heating and stressing on precipitation, the micrographs of materials subjected to various modes of heating and stressing were taken; the static and the dynamic stressing of short duration ( 5 hours) under high stress level $\left(\sigma_{e}=33 \mathrm{~kg} / \mathrm{mm}^{2}\right)$, those of longer duration (500 hours) under low stress level $\left(\sigma_{e}=15 \mathrm{~kg} / \mathrm{mm}^{2}\right)$, heating under no load for the same time interval as the longer duration tests; together with the virgin material. Some increase in amount of precipitates over that of the virgin material are found in both cases after the dynamic creep test and the static creep test of longer duration and also in the case of heating of longer duration under no load. It is likely that the precipitates after longer duration tests are found a little more in the case of dynamic stress than the cases of static stress and of heating under no load. On the other hand, variation of structure is not observed in the tests of short duration under high stress. According to the analysis by electron diffraction, these precipitates are found to be columbium carbides $\left(\mathrm{CbC}, \mathrm{Cb}_{4} \mathrm{C}_{3}\right)$ and chromium carbides $\left(\mathrm{Cr}_{3} \mathrm{C}_{2}, \mathrm{Cr}_{7} \mathrm{C}_{3}, \mathrm{Cr}_{23} \mathrm{C}_{6}\right)$. Of these precipitates, columbium carbides had existed already in the virgin material, and chromium carbides were found after heating or stressing for longer duration.
In such a way, the alternating stress seems. to accelerate the precipitation slightly, but, generally speaking, the precipitation of carbides is mainly caused by heating of longer duration and the influence of stressing is not important in so far as the precipitates observed in electron micrograph are concerned.

As for the relation between the strength characteristics and the precipitation, it must be said that no correspondence is found between them according to the information obtained from the observation of the electron micrographs and the static and the dynamic creep tests stated in thepreceding section. That is, whereas the differences between the rupture lives in the cases of the dynamic and the static stresses were remarkable in the short duration test under high stress, the increase in amount of precipitates was found only in the longer duration test under low stress level. This will be discussed later referring to the results of the other two sorts of tests.

\section{(2) Measurement of hardness}

The Vickers hardness was measured on the same group of materials as that used for the electronmicroscopic examination of structure. The results are shown in Table 3. From these test data, it is seen that the hardness is increased after creep or heating over that of virgin material. In contrast to the case of electron-microscopic structure, the increase in hardness is more remarkable in the short duration test under high stress than in the longer duration test under low stress. This corresponds to the difference between the rupture lives in the case of the dynamic and static stresses, and suggests that the latter resulted from some strengthening effect related to the hardening of the material during the creep process.

(3) Static creep tests after the dynamic creep tests

To investigate the strengthening effect stated in the paragraph (2) further, static creep rupture tests were carried out after dynamic creep tests on

\begin{tabular}{|c|c|c|c|c|c|}
\hline Stress ratio $A$ & $\begin{array}{l}\text { Mean stress } \\
\sigma m \mathrm{~kg} / \mathrm{mm}^{2}\end{array}$ & $\begin{array}{l}\text { Alternating stress } \\
\qquad \sigma a \mathrm{~kg} / \mathrm{mm}^{2}\end{array}$ & $\begin{array}{c}\text { Equivalent static } \\
\text { stress for creep } \\
\sigma e \mathrm{~kg} / \mathrm{mm}^{2}\end{array}$ & $\begin{array}{l}\text { Duration of test } \\
\text { hr }\end{array}$ & $\begin{array}{c}\text { Vickers hardness } \\
\text { load } 50 \mathrm{~kg}\end{array}$ \\
\hline Virgin material & & & & & 147 \\
\hline No load & & & & $\begin{array}{l}500 \text { (duration of } \\
\text { heating) }\end{array}$ & 155 \\
\hline 0 & 15.0 & 0 & 15.0 & 500 & 163 \\
\hline 0.75 & 8.8 & 6.6 & 15.0 & 500 & 171 \\
\hline 0 & 33.0 & 0 & 33.0 & 5 & 214 \\
\hline 0.61 & 21.0 & 12.8 & 33.0 & 5 & 221 \\
\hline 0 & 33.0 & 0 & 33.0 & 10.1 rupture & 228 \\
\hline 0.61 & 21.0 & 12.8 & 33.0 & 219.5 rupture & 232 \\
\hline
\end{tabular}


three specimens under the high stress level where the effect was remarkable. In each of these tests, a dynamic stress was applied to a specimen for a predetermined time duration, and then it was replaced

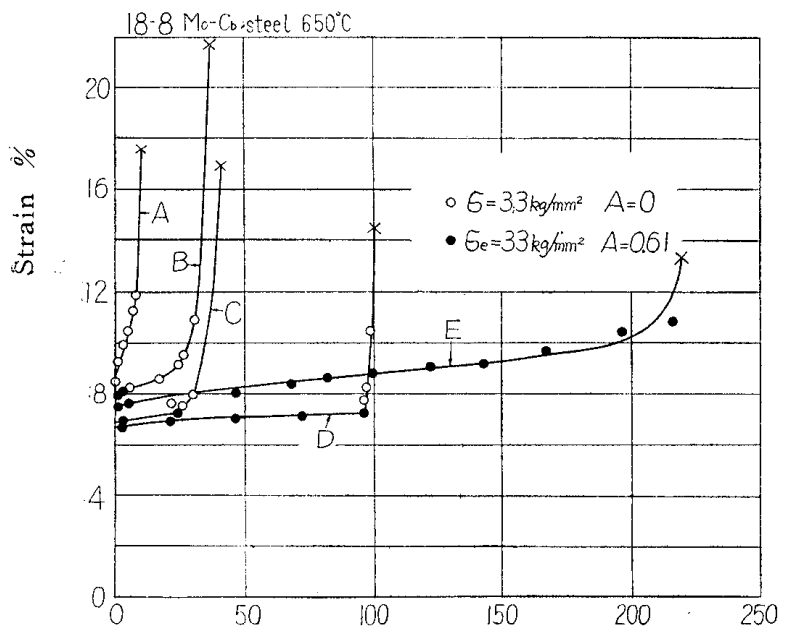

Time hr

Fig. 5 Creep curves obtained in the static creep rupture test after dynamic creep test

$$
\times 2000
$$

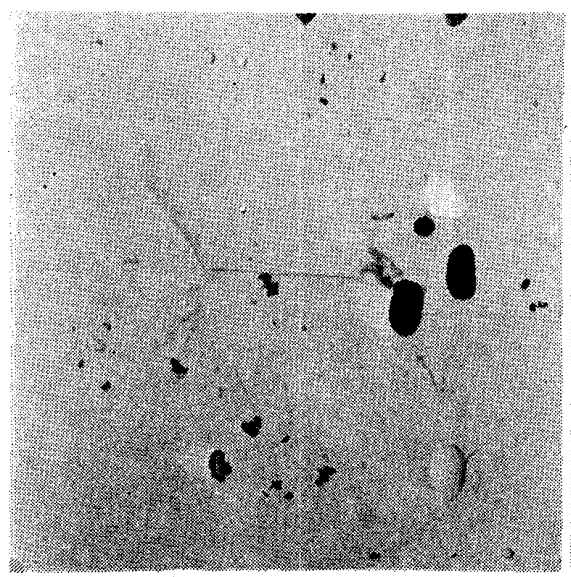

Virgin material

$\times 2000$

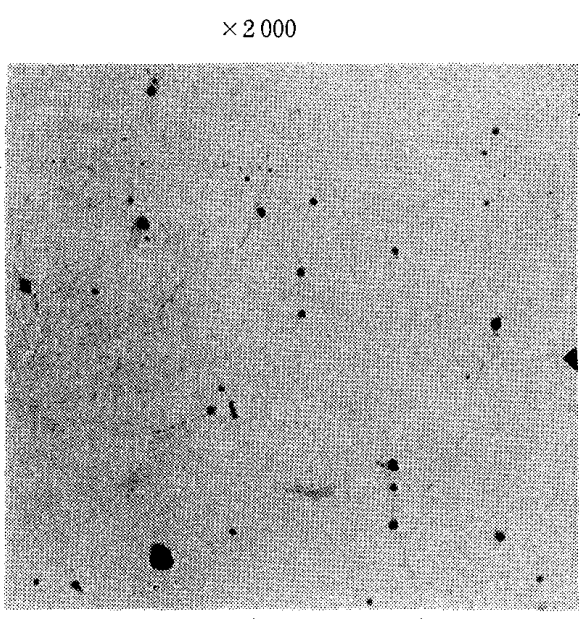

Static creep, $650^{\circ} \mathrm{C}, \sigma=33 \mathrm{~kg} / \mathrm{mm}^{2}, 5 \mathrm{hr}$

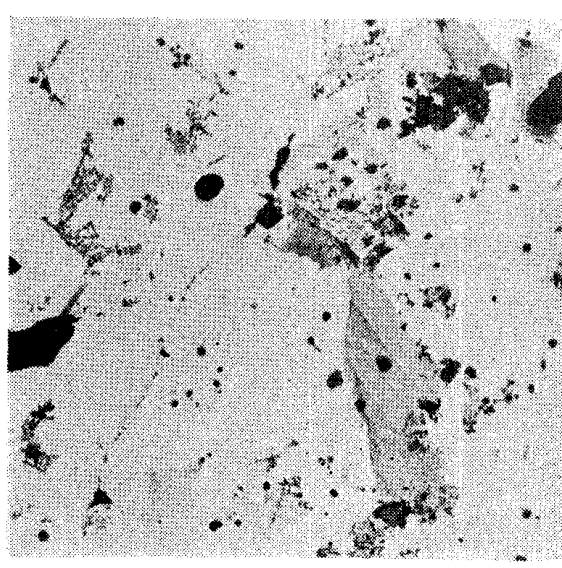

No load, $650^{\circ} \mathrm{C}, 500 \mathrm{hr}$
Static creep, $650^{\circ} \mathrm{C}, \sigma$
$\times 2500$

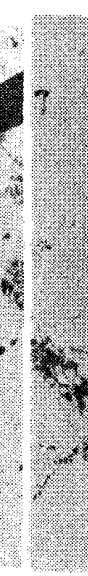

\section{$\times 1 \times 1 \times 10$}
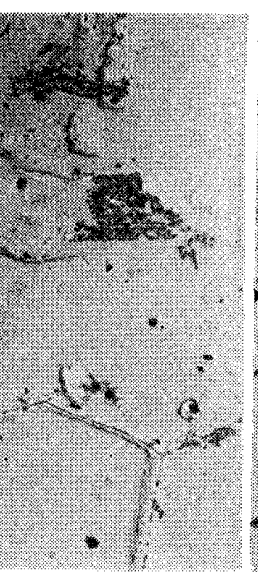

Static creep, $650^{\circ} \mathrm{C}$, $\sigma=15 \mathrm{~kg} / \mathrm{mm}^{2}, 500 \mathrm{hr}$

Fig. 6 Electron micrographs by a static stress of the magnitude which is equal to the equivalent static stress for dynamic condition. The results are summarized in Fig. 5 and Table 4. Some f the specimens, to which the dynamic stress was pplied for 3.3 or 24 hours, showed the rupture ves longer than the specimen without being subted to dynamic stressing. It indicates that these (1) were strengthened by alternating stress during the dynamic creep process. It is to be noted that the strengthening effect by alternating stress is marked in the early stage of dynamic creep process,

Table 4 Duration of alternating stressing and time to rupture for each creep curve shown in Fig. 5

\begin{tabular}{c|c|c} 
& $\begin{array}{c}\text { Duration of alternating } \\
\text { stressing hr }\end{array}$ & \multicolumn{2}{|c}{$\begin{array}{c}\text { Time to rupture in } \\
\text { static creep test hr }\end{array}$} \\
\hline A & 0 & 10.1 \\
B & 3.3 & 33.3 \\
C & 24 & 17 \\
D & 96 & 4.5 \\
E & 219.5 & 0 \\
\hline
\end{tabular}

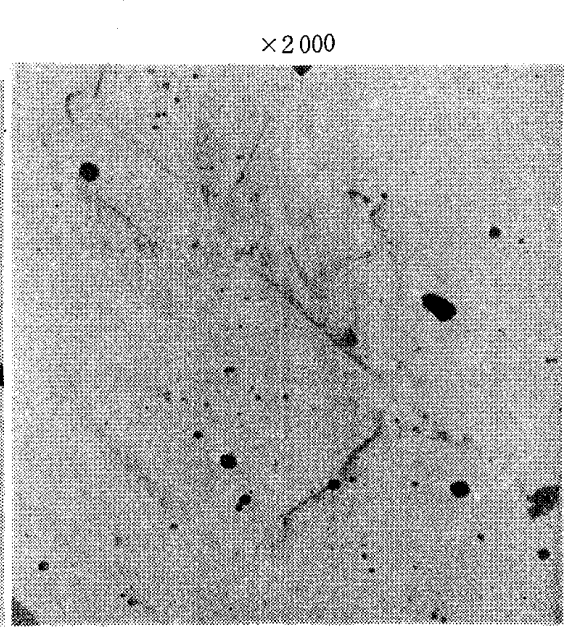

Dynamic creep, $650^{\circ} \mathrm{C}, \sigma e=33 \mathrm{~kg} / \mathrm{mm}^{2}$ $(\sigma m=21.0, \cdot \sigma a=12.8), 5 \mathrm{hr}$

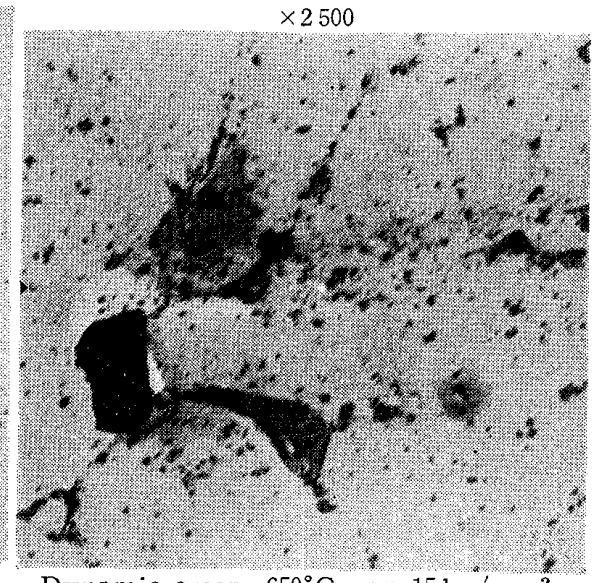

Dynamic creep, $650^{\circ} \mathrm{C}, \sigma e=15 \mathrm{~kg} / \mathrm{mm}^{2}$ $\left(\sigma_{m}=8.8, \sigma_{a}=6.6\right), 500 \mathrm{hr}$ 
rapidly. The elongation on the ruptured specimen is seen to be in correspondence to the variation in rupture lives.

As described in the above, the increase in the amount of precipitates does not correspond to the improvement in strength, but the results of the hardness test and the creep rupture tests after dynamic creep suggest that some strengthening effect of alternating stress related to hardening is concerned with this phenomenon. Moreover, it has been said that the precipitation hardening or age-hardening is due to the fine precipitates of submicroscopic size dispersed in the matrix material ${ }^{(7)(8)}$.

According to the experimental data presented, the strengthening effect is marked in the early stage of dynamic creep test conducted under high stress level, although the precipitation is not found by the electron-microscope. On the other hand, in the later stage of creep test, there is found no strengthening effect notwithstanding precipitates appearing in the electron-microscopic observation. This seems to be a contradiction at first sight, but it can be explained by considering that submicroscopic precipitates mainly affect the strengthening. These submicroscopic precipitates would be influenced by alternating stress and emerge at the early stage of creep, and cause improvement of resistance to creep at the early stage. Thereafter they coagulate in time and become visible under the electron micrograph, losing the strengthening effect at the same time. Thus, it is believed certain that the cause of the difference between the static and dynamic lives lies in the strengthening of the material by alternating stress which would be related to the precipitation harden- ing or age-hardening in submicroscopic scope.

\section{Conclusion}

Dynamic creep and fatigue tests were carried: out with an $18-8 \mathrm{Mo}-\mathrm{Cb}$ steel which has precipitation hardening characteristics to some extent. The results were discussed from the standpoint of the analysis proposed by the authors, which had been proved for its applicability to some materials with stable structure. In this material also, a fairly good agreement was observed between the analytical and the experimental results, although a slight discrepancy was found under some conditions. Judging from the increase in hardness during creep process and the static creep behaviour after subjecting to the dynamic creep tests, it is concluded that this discrepancy has resulted from some strengthening effect of alternating stress related to precipitation hardening or age-hardening of submicroscopic scope.

\section{References}

(1) T. Nishihara, S. Taira, K. Tanaka, and R. Koterazawa:Proc. 6th Japan Nat. Congr. Appl. Mech. $1956,(1957)$, p. 221.

(2) S.Taira, K.Tanaka, and R.Koterazawa: Proc. 2nd Japan Congr. Test. Mat., (1959), p. 55.

(3) S. Taira and R. Koterazawa:Bulletin of JSME, Vol. 4, No. 14 (1961), p. 238.

(4) S. Taira and R. Koterazawa : ibid, Vol. 4, No. 15 (1961), p. 460 .

(5) S. Taira, R. Koterazawa, and Y. Fukumori : Jour. Japan Soc. Test. Mat., Vol. 9, No. 82 (1960), p. 480

(6) W. Koch, A. Schrader, A. Kirsch, u. H. Rohde: Stahl u. Eisen, Jg. 78, Nr. 18 (1958), S. 1251.

(7) H. K. Hardy and T. J. Heal : Progress in Metal Physics, Vol. 5 (1954), p. 143.

(8) A. Constant and G. Delbart : Creep and Fracture of Metals at High Temperature, Proc. of a Symposium held at NPL (1956), p. 191. 